\title{
MECA PARA O TURISMO DE NEGÓCIOS E EVENTOS
}

\author{
Júlio Serson ${ }^{1}$
}

RESUMO: Aborda a importância do turismo internacional e o turismo no Brasil, com base em dados da Organização Mundial de Turismo (OMT) e do World Travel \& Tourism Council (WTTC). Discute, especificamente, oturismo na cidade de São Paulo, ressaltando sua vocação para o turismo de negócios e eventos. Para que isso se concretize há necessidade de um programa de promoção turísticaquepoderiaser centrado, estrategicamente, em dois mercados emissores - o Cone Sul (Argentina, Paraguai e Uruguai) e o Japão -, somado à ampliação de atuação do São Paulo Convention Bureau e à atuação integrada entre os órgãos públicos e a iniciativa privada.

PALAVRAS-CHAVE: Turismo de negócios; turismo de eventos; São Paulo; vocação turística.

\begin{abstract}
A STRACT: The text focuses on the importance of international tourism and tourism in Brazil, basedon data from the World Tourism rganization (IVTO) and the World Travel and Tourism Council (WTTC). It discusses, especifically, tourism issues in the city of São Paulo, stressing its potentiality as a business and convention tourist destination. To achieve that goal, it is necessary to formulate a tourism promotion program, which could be strategically placed in two emission markets - the "southern cone" (Argentina, Paraguay and Uruguay) and Japan - in addiction to the enlarging of the São Paulo Convention and Visitors Bureau strategies and the combined action of public and private sectors.
\end{abstract}

KEY WORDS: Business travel; convention tourism; São Paulo; tourism potentiality.

1 Bacharel em Administração pela Fundação Getúlio Vargas de São Paulo. Curso de Especialização em Hotelaria pela Cornell University. Vice-presidente dos Hotéis Vila-Rica. Coordenador de Turismo da Federação do Comércio do Estado de São Paulo. End. para corresp.: Av. Corifeu de Azevedo Marques, 5577 - 05339 - São Paulo - SP - Brasil. 


\section{TURISMO NO MUNDO E NO BRASIL}

Os dados computados pela Organização Mundial de Turismo (OMT) não deixam dúvidas quanto ao potencial da "indústria turística", que desconhece recessão e tende a crescer ainda mais, tornando-se a principal atividade econômica do mundo. Ademais, as linhas de pesquisa orientadas para a avaliação do tempo de lazer dos trabalhadores têm, invariavelmente, apontado para o crescimento dos espaços livres dedicados ao lazer.

Durante as primeiras décadas deste século, o tempo livre era suficiente para a recuperação do trabalhador. Após a década de 40 - segundo a OMT, o tempo para o lazer vem aumentando, sendo que as horas semanais de trabalho ficaram reduzidas, até o final do século, a 30. As 64 horas disponíveis para lazer, nas décadas de 40 a 50, subiram para 72 horas nas décadas de 50 a 70,77 horas entre 70 a 80 e chegará a 83 horas até o final do século. (Ver Tabela)

Por outro lado, dados da OMT já apontavam, em 1992, a respeitável cifra de US\$ 280 bilhões para a receita mundial do turismo e um movimento de chegadas de 475,6 milhões de pessoas. Considerando-se os efeitos mais globais do turismo na economia mundial, estimativas da World Travel \& Tourism Council(WTTC), realizadas pela Wharton Econometrics Forecasting Association (WEFA), incluindo os efeitos diretos e indiretos desses gastos, indicam o seguinte:

a) um movimento financeiro gerado pelo turismo da ordem de US\$ 3,5 trilhões em 1993, o que corresponde a aproximadamente 10\% do PIB mundial;

b) 127 milhões de empregos no mundo em 1993, correspondendo a $6,6 \%$ da oferta total de empregos, o que equivale a $1 \mathrm{~cm}$ cada 15 empregos. (ABAV, 1993)

Do "bolo" dos gastos diretos do turismo internacional, o Brasil recebeu cerca de 1,6 milhão de turistas estrangeiros em 1993, que geraram divisas da ordem de US\$ 1.5 bilhão; no mesmo período esse desempenho foi dobrado pela Argentina, embora não disponha de um trade do porte do brasileiro. Segundo ainda o WTTC, o setor gerou, em 1992, no Brasil, direta ou indiretamente, US\$ 35 bilhões, o que corresponde a cerca de $8 \%$ de seu PIB e $1,3 \%$ do PIB mundial. Em 1994, a receita deverá chegar a US\$ 45 bilhões, correspondendo a 10\% do PIB brasileiro. (ABAV, 1993)

Ainda, a situação e expectativa é positiva diante dos dados da Bolsa de Negócios, realizada em abril de 1993, onde se comercializou US\$ 1 bilhão de pacotes turísticos para a temporada brasileira de 1993/94 e já garantiu milhão de turistas. A EMBRATUR pretende acrescer a esse número mais 1,5 milhão de visitantes, atraídos por uma campanha publicitária de US\$10 milhões, em que enfatiza as vantagens econômicas das viagens realizadas durante a baixa estação, quando muitos hotéis chegam a ficar com $50 \%$ de sua ocupação ociosa.

O ideal seria que o Brasil investisse cerca de US\$ 28 milhões anualmente na "indústria turística", ou seja, $2 \%$ da arrecadação com o setor, como recomenda a OMT. Contudo, essa realidade está cada dia mais distante num país com tantas carĉncias sociais, que não deixam ver no turismo a nova fonte fomentadora de desenvolvimento e empregos, pela sua capacidade de gerar e absorver mão-de-obra com rapidez, distribuindo renda.

Com base na análise da matriz insumo-produto, a EMBRATUR revela o bom desempenho econômico da "indústria turística" brasileira em 1989: gerou $2,5 \%$ do PIB nacional, $1,9 \%$ dos tributos diretos e indiretos arrecadados pelos cofres públicos, e empregou $2,6 \%$ da população economicamente ativa do país. Contudo, para "azeitar" esse setor, é necessário um mínimo de investimentos, com melhoramento dos equipamentos turísticos, ampliação da infra-estnutura e aprimoramento dos serviços de transportes e segurança, e treinamento da mão-de-obra. Tudo isso resulta num produto turístico dotado de qualidade, preço e diversificação. Portanto, com competitividade para superar outras destinações internacionais.

\section{TURISMO EM SÃO PAULO}

No caso de São Paulo, especificamente, pesquisa da EMBRATUR de 1992 apontou que a cidade está em quinto lugar entre as mais visitadas pelos turistas estrangeiros, sendo suplantada pelo Rio de Janeiro, Florianópolis, Camboriú e Foz do Iguaçu. Mais: a maioria dos visitantes vem do Cone Sul, correspondendo, em média, a $40 \%$ do seu fuxo internacional receptivo. Embora São Paulo ofereça atrativos que seduzam o turista a passeio, como vida noturna, parque hoteleiro de nível internacional, comércio forte e diversificado e atividade cultural intensa, a vocação da cidade está ligada aos negócios, até pelo seu perfil de "carro-chefe" da economia brasileira.

São Paulo reúne mais de $50 \%$ do PIB nacional e, certamente, tem condições de se transformar no eixo do turismo de negócios do país. De acordo com os conceitos emitidos pela escassa bibliografia no campo turístico, entenda-se por turismo de negócios e eventos o fluxo turístico relacionado aos movimentos negociais e promocionais, desenvolvidos no mix dos eventos: seminários, reuniões, convenções de venda, feiras, exposições, congressos técnicos e científicos, entre outros. 
No decorrer deste artigo, adota-se o conceito de evento segundo MINERVINO, (1992):

Acontecimento previamente planejado, a ocorrer num mesmo tempo e lugar como forma de minimizar esforços de comunicação, objetivando o engajamento de pessoas a uma idéia ou ação.

São Paulo reúne, também, o maior complexo de comunicação do país, sendo responsável por quase $70 \%$ dos inputs da mídia nacional. Estabelecese, assim, o sistema pelo qual a maior Capital do país poderá ser a Meca do Turismo Nacional.

Para marcar este perfil e tirar proveito do potencial da cidade, que compreende $23 \%$ dos hotéis brasileiros, $42,2 \%$ das transportadoras e $34 \%$ das agências de viagem do país, seria necessário formular uma política voltada para o segmento de feiras c congressos. O Chile, por exemplo, vem concretizando iniciativas coordenadoras no campo da mineração e indústria aeronáutica, promovendo congressos e exposições ligados a esses setores. Com um potencial muito maior, São Paulo sedia atualmente apenas $13 \%$ dos eventos internacionais, gerando US\$ 100 milhões referentes à locação de espaços e 30 mil empregos diretos.

Com a dinamização do turismo de negócios, São Paulo teria muito a ganhar. Poderia, por exemplo, colocar um ponto final na ociosidade do setor hoteleiro. Dadios disponíveis apontam que, em 1986, a taxa média de ocupação dos hotéis paulistas ficou em $60,3 \%$. Nos anos seguintes, a taxa fixou-se em $50 \%$ nos melhores casos, caindo em até $30 \%$ nos mais críticos, evidenciando a dificuldade do setor, considerado o melhor do país, em atingir um patamar de desenvolvimento sem necessitar enfrentar percalços. Essa situação compromete toda a "indústria turística", uma vez que o setor hoteleiro é a base dessa engrenagem, com um destacado efeito multiplicador de renda e emprego.

\section{QUE FAZER?}

Uma estratégia para conquistar mercado para o turismo de negócios passa necessariamente por um programa de promoçãoturística, concentrado em dois mercados emissores. Um, o Cone Sul (Argentina, Paraguai e Uruguai) promissor pela proximidade geográfica e econômica e favorecido pela instalação do Mercosul. O outro é o Japão.

São Paulo, devido às suas ligações históricas, culturais e econômicas com o País do Sol Nascente e da tecnologia, decorrente da imigração, pode fazer dessa aproximação uma porta de entrada para feiras e congressos internacionais promovidos por empresários japoneses, gerando, ainda, mais divisase firmando a cidade como a Meca do Turismo de Negócios na América Latina.

Com a definição de uma política de turismo, na qual esteja incluídoum programa de incentivo ao turismo de negócios, ampliando a atuação do São Paulo Convention Bureau, o sonho de transformar São Paulo em meca dos eventos internacionais pode se tornar realidade. Mas, para executar esse projeto, o governo paulista precisa contar com a soma dos recursos de todos os segmentos do trade turístico. $\mathrm{O}$ trabalho de promoção deve se concentrar sobre o perfil progressista e moderno da capital paulista, visando reverter junto ao empresariado estrangeiro a imagem negativa da nossa sociedade.

\section{REFERÊNCIAS BIBLIOGRÁFICAS}

ABAV - Associação Brasileira de Agentes de Viagens. 1993. O que as autoridades e os governos e os parlamentares devem saber sobre turismo. Turismo é Indístria. São Paulo, 2 ed. out. MINERVINO, Ana Cristina M. Giácomo. 1992. Eventos: líder de opinião, motivação e público. São Paulo, 165 p. (Mestrado) - ECA-USP. 
TABELA - EVOLUCÇ̃̃O DO TEMPO LIVRE

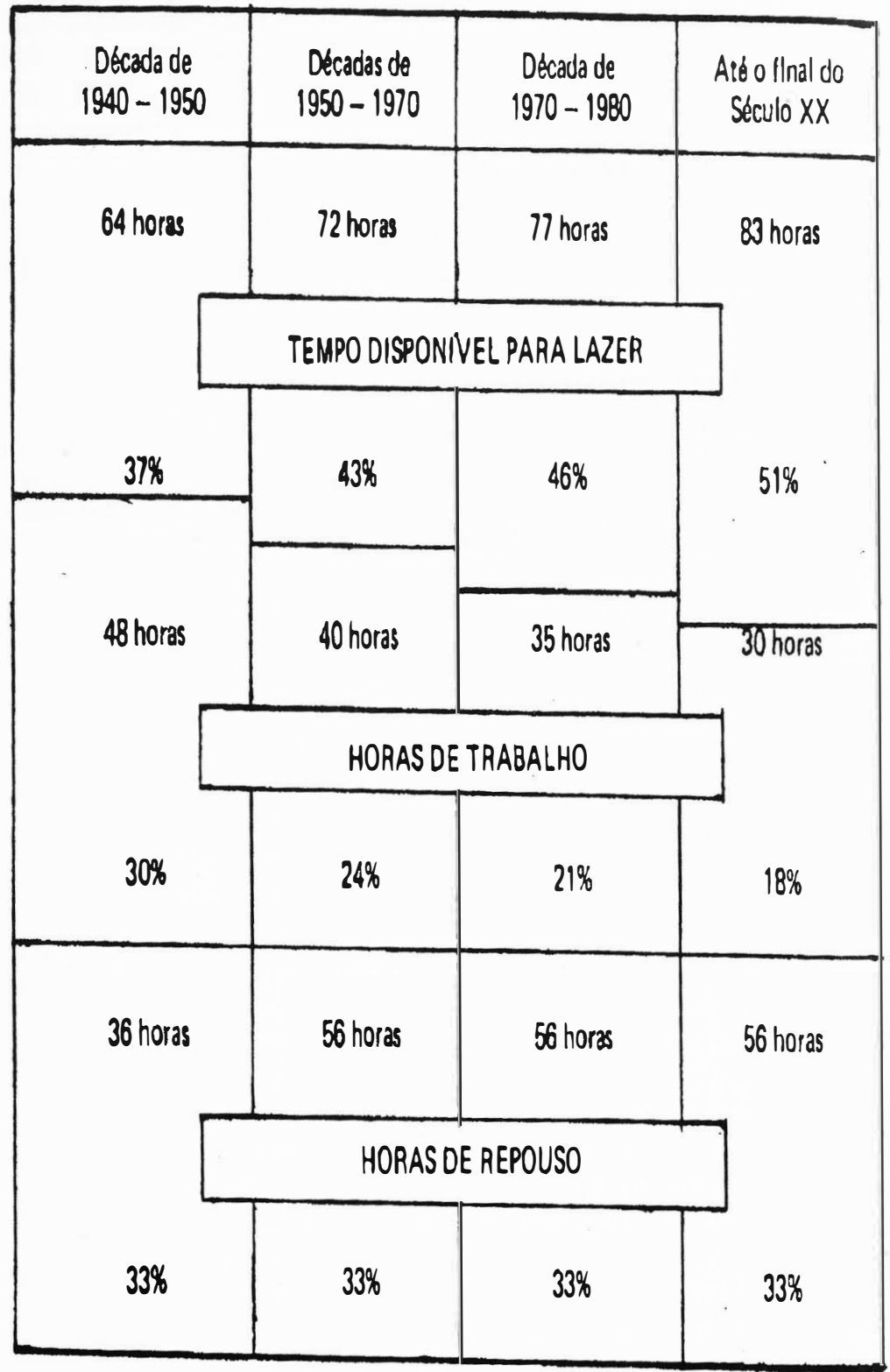

Fonte: Organizecso Mundial de Turismo - OMT. 